\title{
Marked cerebral atrophy is correlated with kidney dysfunction in nondisabled adults
}

\author{
Yusuke Yakushiji ${ }^{1}$, Yusuke Nanri ${ }^{1}$, Tatsumi Hirotsu ${ }^{2}$, Masashi Nishihara ${ }^{3}$, Megumi Hara ${ }^{4}$, Junko Nakajima ${ }^{2}$, \\ Makoto Eriguchi $^{1}$, Masanori Nishiyama ${ }^{2}$, Hideo Hara ${ }^{1}$ and Koichi Node ${ }^{5}$
}

The relationship between kidney dysfunction, such as chronic kidney disease (CKD), and brain morphology has attracted increasing attention, but the association between kidney dysfunction and cerebral atrophy has yet to be determined. The purpose of this study was to clarify the relationship between kidney function and a substantial degree of cerebral atrophy. A total of 610 consecutive Japanese adults without neurological disorders who had undergone health screening tests of the brain were studied prospectively. Magnetic resonance imaging was performed using a 1.5-T scanner. Using a computer-assisted processing system, the percentage of cerebrum atrophy (\%Cerebrum atrophy) was calculated as an index of cerebral atrophy. Atrophy was defined as $>2$ s.d.s below the mean \%Cerebrum atrophy. The glomerular filtration rate (GFR) was estimated using the revised equations for estimated GFR from serum creatinine in Japan. Kidney function variables included the GFR value and the prevalence of subjects with GFR $<60 \mathrm{ml} \mathrm{min}^{-1}$ per $1.73 \mathrm{~m}^{2}$. Cerebral atrophy was found in $25(4.1 \%)$ cases. Univariate analysis showed that age, male sex, hypertension, each kidney function variable, white matter hyperintensities and lacunae were associated with cerebral atrophy. On logistic regression analysis, GFR (odds ratio (OR), 0.64; 95\% confidence interval (CI), 0.42-0.98) and GFR $<60 \mathrm{ml} \mathrm{min}^{-1}$ per $1.73 \mathrm{~m}^{2}(\mathrm{OR}, 5.93 ; 95 \% \mathrm{Cl}, 1.82-19.27)$ were significantly associated with cerebral atrophy. On subanalysis, GFR $<60 \mathrm{ml} \mathrm{min}^{-1}$ per $1.73 \mathrm{~m}^{2}$ was significantly associated with cortical atrophy (OR, 3.23; 95\% CI, 1.15-9.11). Decreased GFR was significantly associated with cerebral atrophy, indicating that treatment of CKD may control age-related degenerative processes of the brain.

Hypertension Research (2010) 33, 1232-1237; doi:10.1038/hr.2010.171; published online 14 October 2010

Keywords: cerebral atrophy; chronic kidney disease; glomerular filtration rate; kidney function

\section{INTRODUCTION}

Generalized cerebral atrophy progresses gradually and subclinically with aging in middle age. However, in elderly people, it increases further and can cause cognitive impairment and decrease activities of daily living. Therefore, it is important to identify the preventable factors that are related to age-specific, generalized cerebral atrophy during the asymptomatic period.

Traditional cardiovascular risk factors, including hypertension, ${ }^{1}$ diabetes mellitus, ${ }^{2}$ hyperlipidemia, ${ }^{3}$ alcohol use ${ }^{4}$ and smoking, ${ }^{3}$ have been implicated as accelerating the atrophic process. In recent years, kidney dysfunction, such as chronic kidney disease (CKD), has also been accepted as a potent cardiovascular risk factor, ${ }^{5-7}$ and it is being increasingly investigated with respect to its relevance to subclinical magnetic resonance imaging (MRI) abnormalities, with studies examining the correlations between creatinine clearance and cerebral lacunae; ${ }^{8}$ cystatin $\mathrm{C}$ and cerebral lacunae; ${ }^{9}$ microalbuminuria and small vessel disease (SVD); ${ }^{10,11}$ and decreased glomerular filtration rate (GFR) and white matter hyperintensities (WMHs). ${ }^{12,13}$ In addition, a small number of studies have investigated whether kidney function affects generalized cerebral atrophy; ${ }^{11,12}$ however, their results were controversial.

Thus, an analysis of the relationship between kidney function and subclinical age-specific cerebral atrophy was undertaken in a sample of independently living adults with no history of neurological disorders.

\section{METHODS}

Subjects

A total of 809 consecutive adults underwent health screening tests of the brain in our center at their own expense between December 2005 and May 2008. The same system of health screening tests of the brain was described in previous studies. ${ }^{14,15}$ These individuals were considered potential study subjects. To be included, subjects had to meet the following criteria: (1) age $\geqslant 30$ years; (2) no disability in instrumental activities of daily living; (3) ability to independently attend visits for health screening tests of the brain; and (4) voluntary provision of written, informed consent. The exclusion criteria were (1) inability to undergo cerebral MRI; (2) history of symptomatic kidney disease; (3) history

${ }^{1}$ Division of Neurology, Department of Internal Medicine, Saga University School of Medicine, Saga, Japan; ${ }^{2}$ Yuai-Kai Oda Hospital, Kashima, Saga, Japan; ${ }^{3}$ Department of Radiology, Saga University School of Medicine, Saga, Japan; ${ }^{4}$ Department of Preventive Medicine, Saga University School of Medicine, Saga, Japan and ${ }^{5}$ Division of Cardiology, Department of Internal Medicine, Saga University School of Medicine, Saga, Japan Correspondence: Dr Y Yakushiji, Division of Neurology, Department of Internal Medicine, Saga University School of Medicine, 5-1-1 Nabeshima, Saga 849-8501, Japan. E-mail: yakushij@cc.saga-med.ac.jp

Received 14 February 2010; revised 2 June 2010; accepted 27 June 2010; published online 14 October 2010 
of neurological disorder or brain injury; and (4) abnormal neurological examination. All protocols were approved by the institutional review board. Of the 809 potential subjects, 135 subjects refused to enroll, 8 had a history of neurological disorder or brain injury and 1 had a history of symptomatic kidney disease (nephrotic syndrome). Of the remaining 665 subjects, 4 subjects displayed motion artifacts on MRI, 1 had a huge subarachnoid cyst in the cerebrum, 1 could not undergo cerebral MRI because of severe claustrophobia and data required for the analysis were incomplete in 49 subjects (missing MRI, $n=10$; missing laboratory data, $n=18$; missing educational level, $n=21$ ). As a result, 610 subjects (302 men, 308 women) with a mean age of 56.4 years (standard deviation (s.d.), 9.9; range, 33-85 years) were studied prospectively.

\section{Baseline assessment}

Age, sex, past history of ischemic heart diseases, family history of stroke, smoking status, presence of hypertension, diabetes mellitus or hyperlipidemia, blood pressure, years of education and mini-mental state examination (MMSE) score were recorded as baseline clinical characteristics. Hypertension was defined as systolic blood pressure $>140 \mathrm{~mm} \mathrm{Hg}$ and/or a diastolic blood pressure $>90 \mathrm{~mm} \mathrm{Hg}$ or use of antihypertensive medication. Diabetes mellitus was defined as fasting serum glucose level $\geqslant 126 \mathrm{mg}$ per $100 \mathrm{ml}$, hemoglobin Alc level $\geqslant 6.5 \%$ or use of antidiabetic medication. Hyperlipidemia was defined as fasting serum total cholesterol level $\geqslant 220 \mathrm{mg}$ per $100 \mathrm{ml}$ and/or fasting serum triglyceride levels $\geqslant 200 \mathrm{mg}$ per $100 \mathrm{ml}$ and/or use of antihyperlipidemic agents. Patients who were smokers at the time of their visit were classified as current smokers. Past history of ischemic heart disease, family history of stroke and duration of education were obtained from each subject.

\section{Kidney function}

To examine the relationship between kidney function and cerebral atrophy, two variables, the GFR value and the prevalence of subjects with GFR $<60 \mathrm{ml} \mathrm{min}^{-1}$ per $1.73 \mathrm{~m}^{2}$, which is used as a cutoff point for the diagnosis of CKD, were used. GFR was estimated using the revised equations for estimated GFR from serum creatinine in $\operatorname{Japan}^{16}$ as follows:

$$
\begin{aligned}
\text { GFR }= & 194 \times \text { serum creatinine }(\text { mg per } 100 \mathrm{ml})^{-1.094} \\
& \times \text { age }^{-0.287}(\times 0.739 \text { if female }) .
\end{aligned}
$$

The level of serum creatinine was determined by an enzymatic method with L-type creatinine M (Wako Pure Chemical Industries, Tokyo, Japan) using a Hitachi 7080 automated analyzer (Hitachi High-Technologies, Tokyo, Japan).

\section{Clinical assessment}

All subjects were initially examined by general physicians. Subjects suspected of having neurological deficits or abnormal MRI findings were subsequently examined neurologically by a certified neurosurgeon or neurologist.

\section{MRI}

MRI was performed using a 1.5-T scanner (EXCELART Vantage, version 7.0; Toshiba Medical Systems, Tokyo, Japan) in the axial plane with the following parameters: T1-weighted image, repetition time (TR) $550 \mathrm{~ms}$, echo time (TE) $12 \mathrm{~ms}$, flip angle (FA) $80^{\circ}$ and matrix $352 \times 352$; T2-weighted image (T2WI), TR $4000 \mathrm{~ms}$, TE $108 \mathrm{~ms}, \mathrm{FA} 90^{\circ}$ and matrix $400 \times 400$; fluid-attenuated inversion recovery imaging, TR $10000 \mathrm{~ms}$, TE $96 \mathrm{~ms}$, inversion time $2500 \mathrm{~ms}$, FA $90^{\circ}$ and matrix $352 \times 352$. Each parameter was obtained with the same section thickness $(7 \mathrm{~mm})$, interslice gap $(1.4 \mathrm{~mm})$ and field of view $\left(220 \times 220 \mathrm{~mm}^{2}\right)$. MRI data were transferred for digital imaging and communication in medicine images from the MRI unit to a Windows-based computer.

Using a computer-assisted processing system (Image J version 1.41; National Institutes of Health, Bethesda, MD, USA) and the methods of Koga et al., ${ }^{17}$ the percentage cerebrum value (\%Cerebrum atrophy) was calculated as an index of cerebral atrophy (Figure 1). First, skull stripping of a T2WI of digital imaging and communication in medicine, involving two slices above the pineal body, was performed. Second, the intracranial space was divided into two areas, the cerebral parenchyma and cerebrospinal fluid (CSF) space, using

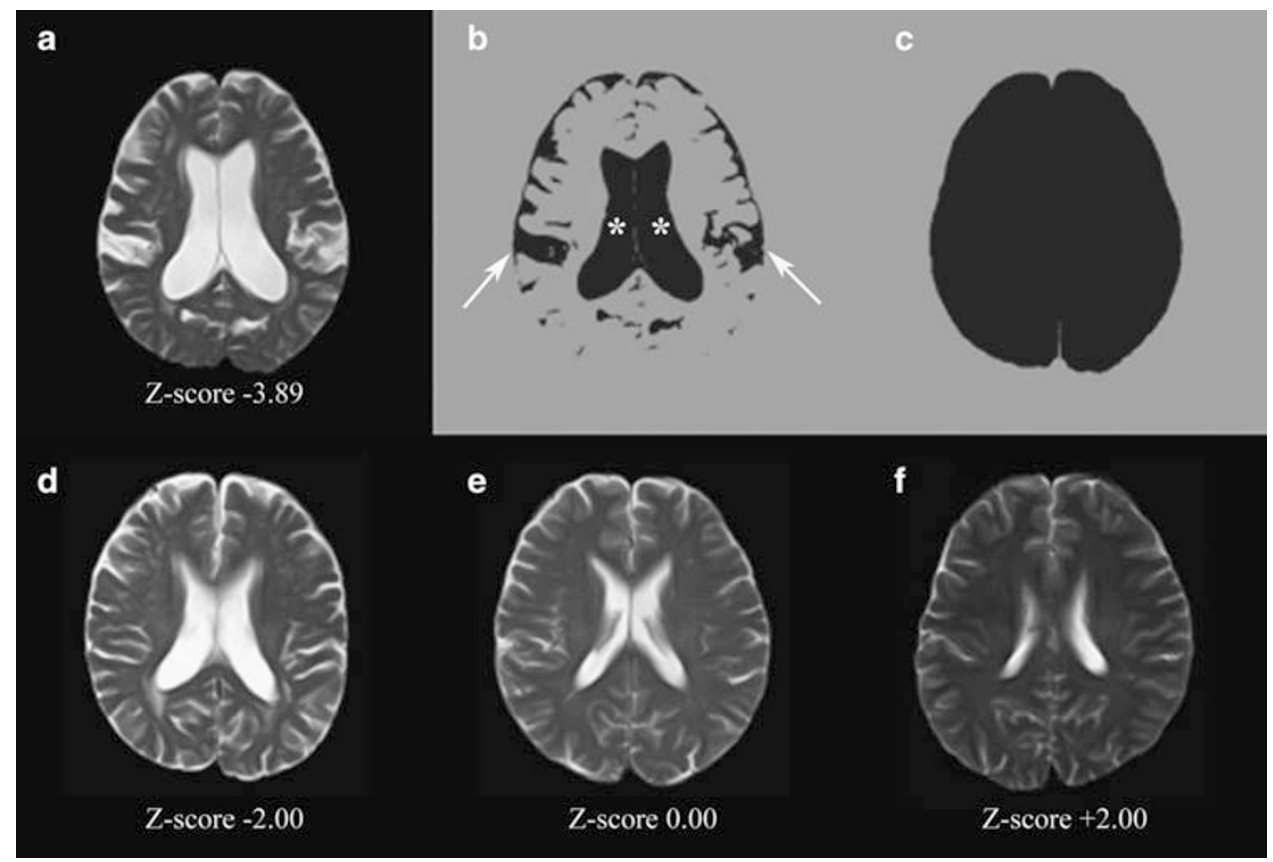

Figure 1 Representative images (a-c: of subject with \%Cerebrum $z$-score -3.89 ) explain the procedure of measuring \%Cerebrum, \%Periventricular and \%Cortical atrophy using a computer-assisted processing system. (a) An image after skull stripping. (b) Measurement of the cerebrospinal fluid space (asterisks, ventricular space; arrows, sulcal space). (c) Measurement of intracranial space. \%Cerebrum atrophy=(intracranial space-cerebrospinal fluid space)/intracranial space $\times 100 \quad(\%) ; \quad \%$ Periventricular atrophy=(intracranial space-ventricular space)/intracranial space $\times 100 \quad(\%) ; \quad \%$ Cortical atrophy $=$ (intracranial space-sulcal space)/intracranial space $\times 100$ (\%). (d-f) Representative images of subjects with \%Cerebral atrophy $z$-scores of -2.00 , 0.00 and +2.00 , respectively. 
a semiautomatic method with an appropriate threshold. The CSF space was separated into the areas of the ventricular CSF and of the sulcal CSF. Then, the areas of the intracranial space, cerebral parenchyma and CSF (ventricular CSF plus sulcal CSF) were quantitatively measured to count the pixels with a given intensity. In addition to \%Cerebral atrophy, which was used in the main analysis, the degree of atrophy associated with ventricular enlargement (\%Periventricular atrophy), as well as cortical atrophy (\%Cortical atrophy), was used in the sub-analysis. Each index of atrophy was calculated as follows: \%Cerebral atrophy $=$ (the area of intracranial space-the area of CSF)/the area of intracranial space; \%Periventricular atrophy $=$ (the area of intracranial space-the area of ventricular CSF)/the area of intracranial space; \%Cortical atrophy $=$ (the area of intracranial space-the area of sulcal CSF)/the area of intracranial space (Figure 1). Atrophy was defined as more than 2 s.d.s below the mean for each index. To enable better comparison of the effects of GFR on different types of atrophy, the $z$-score for each atrophy type was calculated separately: $z$-score $=$ (individual percentage of atrophy-mean percentage of atrophy)/s.d. Representative images of subjects with \%Cerebral atrophy $z$-scores of $-2.00,0.00$ and +2.00 are shown in Figures $1 \mathrm{~d}-\mathrm{f}$, respectively.

The severity of WMH and the presence of lacunae were independently reviewed by two authors (WMH: ME, YY; lacunae: YN, MN), who were blinded to subject data. The severity of WMH on T2WI and fluid-attenuated inversion recovery imaging was rated according to the Fazekas scale (grade 1, punctate; grade 2, early confluence; and grade 3 , confluent). ${ }^{18}$ Lacunae were defined as focal, sharply demarcated lesions $>3 \mathrm{~mm}$ in diameter showing high intensity on T2WI and fluid-attenuated inversion recovery imaging and low intensity on T1-weighted image. The inter-rater reliabilities for WMH and lacunae, expressed as Chohen's kappa, were 0.62 and 0.72 , respectively. The intra-rater reliabilities of rating such findings were determined on 50 randomly selected scans that were scored twice and then expressed as Chohen's kappa. Each value ranged from 0.64 to 0.82 .

\section{Statistics}

Statistical analysis was performed using the Statistical Package for the Social Sciences version 11.0 software (SPSS, Chicago, IL, USA). To compare baseline characteristics and MRI findings between cerebral atrophy and normal groups, the $\chi^{2}$-test and the Mann-Whitney $U$-test were used as appropriate. Clinical variables with $P<0.20$ on univariate analysis, in addition to age and sex, were entered into the multiple logistic regression analysis to determine the significant, independent factors contributing to cerebral atrophy, periventricular atrophy and cortical atrophy. Values of $P<0.05$ were considered statistically significant.

\section{RESULTS}

The values of \%Cerebrum atrophy and its $z$-score ranged from 70.49 to $94.72 \%$ and from -3.89 to 2.22 , respectively. A total of $25(4.1 \%)$ subjects showed \%Cerebrum atrophy $>2$ s.d.s below the mean ( $z$-score less than -2.0$)$ and were judged to have cerebral atrophy. The values of \%Periventricular atrophy and its $z$-score ranged from 78.68 to $98.26 \%$ and from -4.91 to 2.17 , respectively. A total of $21(3.4 \%)$ subjects showed \%Periventricular atrophy $>2$ s.d.s below the mean $(z$-score less than -2.0$)$ and were judged to have periventricular atrophy. The values of \%Cortical atrophy and its $z$-score ranged from 84.79 to $98.07 \%$ and from -4.25 to 2.12 , respectively. In total, 23 (3.8\%) subjects showed \%Cortical atrophy $>2$ s.d.s below the mean $(z$-score less than -2.0$)$ and were judged to have cortical atrophy. The GFR value ranged from 34.49 to $158.89 \mathrm{ml} \mathrm{min}^{-1}$ per $1.73 \mathrm{~m}^{2} ; 62$ subjects $(10.2 \%)$ had GFR $<60 \mathrm{ml} \mathrm{min}^{-1}$ per $1.73 \mathrm{~m}^{2}$.

The baseline clinical characteristics, kidney function variables and MRI findings of the cerebral atrophy and normal groups are shown in Table 1. Cerebral atrophy was significantly associated with aging, male sex, hypertension, lower MMSE score, lower GFR, GFR $<60 \mathrm{ml} \mathrm{min}^{-1}$ per $1.73 \mathrm{~m}^{2}$, severity of $\mathrm{WMH}$ and presence of lacunae.
Table 1 Clinical features, kidney function and MRI findings of the normal and cerebral atrophy groups

\begin{tabular}{|c|c|c|c|}
\hline Variables & $\begin{array}{c}\text { Normal, } \\
\mathrm{n}=585 \\
(95.9 \%)\end{array}$ & $\begin{array}{c}\text { Cerebral } \\
\text { atrophy, } \\
\mathrm{n}=25(4.1 \%)\end{array}$ & P-value \\
\hline \multicolumn{4}{|l|}{ Clinical variables } \\
\hline $\begin{array}{l}\text { Age; median (IQR), } \\
\text { years }\end{array}$ & $56.2(49.3-63.0)$ & $70.5(66.5-78.1)$ & $<0.0001$ \\
\hline Sex; male, $n(\%)$ & $281(48.0)$ & $21(84.0)$ & $<0.0001$ \\
\hline Hypertension, $n(\%)$ & $191(32.6)$ & $14(56.0)$ & 0.015 \\
\hline Diabetes mellitus, $n(\%)$ & $56(9.6)$ & $1(4.0)$ & 0.348 \\
\hline Hyperlipidemia, $n(\%)$ & $289(49.4)$ & $12(48.0)$ & 0.891 \\
\hline Smoking, $n(\%)$ & 109 (18.6) & $3(12.0)$ & 0.402 \\
\hline $\begin{array}{l}\text { Ischemic heart disease, } \\
n(\%)\end{array}$ & $17(2.9)$ & $1(4.0)$ & 0.752 \\
\hline $\begin{array}{l}\text { Family history of stroke, } \\
n(\%)\end{array}$ & $171(29.2)$ & $9(36.0)$ & 0.467 \\
\hline $\begin{array}{l}\text { SBP; median (IQR), } \\
\mathrm{mm} \mathrm{Hg}\end{array}$ & $122(110-134)$ & 130 (112-139) & 0.114 \\
\hline $\begin{array}{l}\text { DBP; median (IQR), } \\
\mathrm{mm} \mathrm{Hg}\end{array}$ & $76(68-84)$ & $80(74-82)$ & 0.187 \\
\hline $\begin{array}{l}\text { Education; median } \\
\text { (IQR), years }\end{array}$ & $12.0(12.0-16.0)$ & $12.0(9.0-12.5)$ & 0.203 \\
\hline $\begin{array}{l}\text { MMSE score, } \\
\text { median (IQR) }\end{array}$ & $30(29-30)$ & $29(27-30)$ & $<0.0001$ \\
\hline \multicolumn{4}{|l|}{ Kidney functions } \\
\hline 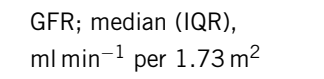 & $77.3(68.3-86.3)$ & $63.6(54.6-75.5)$ & $<0.0001$ \\
\hline GFR $<60, n(\%)$ & $52(8.9)$ & $10(40.0)$ & $<0.0001$ \\
\hline \multicolumn{3}{|l|}{ MRI findings } & \\
\hline None & $283(48.4)$ & $3(12.0)$ & $<0.0001$ \\
\hline Punctate & $226(38.6)$ & $6(24.0)$ & \\
\hline Early confluent & $67(11.5)$ & $10(40.0)$ & \\
\hline Confluent & $9(1.5)$ & $6(24.0)$ & \\
\hline Presence of lacunes, $n(\%)$ & $22(3.8)$ & $4(16.0)$ & 0.003 \\
\hline
\end{tabular}

Abbreviations: DBP, diastolic blood pressure; GFR, glomerular filtration rate; IQR, interquartile range; MMSE, mini-mental state examination; $\mathrm{MRI}$, magnetic resonance imaging; SBP, systolic blood pressure; $\mathrm{WMH}$, white matter hyperintensity.

Continuous variables are compared using the Mann-Whitney U-test between the groups, and presented as median with IQRs.

Because both kidney function variables were significantly associated with cerebral atrophy on univariate analysis, whether each was independently associated with cerebral atrophy was then determined. Primary logistic regression analysis was adjusted for age, sex, hypertension, WMH and lacunae (Table 2: models 1 and 3). Systolic blood pressure and diastolic blood pressure, which were thought to be confounding factors of history of hypertension, also tended to be associated with cerebral atrophy. However, history of hypertension was used for multivariate analysis, because it displayed a lower probability value than systolic blood pressure and diastolic blood pressure. Of the 205 subjects with a history of hypertension, 125 had used some antihypertensive drugs; however, information about the duration of hypertension and the antihypertensive regimens was not obtained. Although the MMSE score should be considered a result, not a risk factor, of cerebral atrophy, it was also included in the final logistic regression analysis (Table 2: models 2 and 4). Thus, each kidney 
Table 2 Logistic regression analysis of factors relevant to cerebral atrophy

\begin{tabular}{|c|c|c|c|c|c|c|c|c|}
\hline Variables & OR $(95 \% \mathrm{Cl})$ & P-value & OR $(95 \% \mathrm{Cl})$ & P-value & OR $(95 \% \mathrm{Cl})$ & P-value & OR $(95 \% \mathrm{Cl})$ & P-value \\
\hline Male & $4.85(1.45-16.20)$ & 0.010 & $4.87(1.46-16.17)$ & 0.010 & $5.19(1.54-17.45)$ & 0.008 & $5.31(1.57-17.92)$ & 0.007 \\
\hline Hypertension & $0.69(0.24-1.99)$ & 0.495 & $0.74(0.26-2.16)$ & 0.583 & $0.63(0.22-1.87)$ & 0.407 & $0.67(0.23-2.00)$ & 0.477 \\
\hline WMH & $1.98(1.10-3.54)$ & 0.022 & $2.02(1.12-3.63)$ & 0.020 & $2.34(1.26-4.33)$ & 0.007 & $2.39(1.28-4.45)$ & 0.006 \\
\hline Kidney function & $0.64(0.42-0.98)$ & 0.042 & $0.65(0.42-1.00)$ & 0.048 & $5.93(1.82-19.27)$ & 0.003 & $5.86(1.80-19.16)$ & 0.003 \\
\hline
\end{tabular}

Abbreviations: $95 \% \mathrm{Cl}$, 95\% confidence interval; GFR, glomerular filtration rate; MMSE, mini-mental state examination; OR, odds ratio; WMH, white matter hyperintensities. Variables were analyzed using the value of GFR (per $10 \mathrm{ml} \mathrm{min}^{-1}$ per $1.73 \mathrm{~m}^{2}$ ) in Models 1 and 2 , and subject with GFR $<60 \mathrm{ml} \mathrm{min}^{-1}$ per $1.73 \mathrm{~m}^{2}$ in Models 3 and 4 . Analyses were performed without the MMSE score in Models 1 and 3, and with the MMSE score in Models 2 and 4.

a

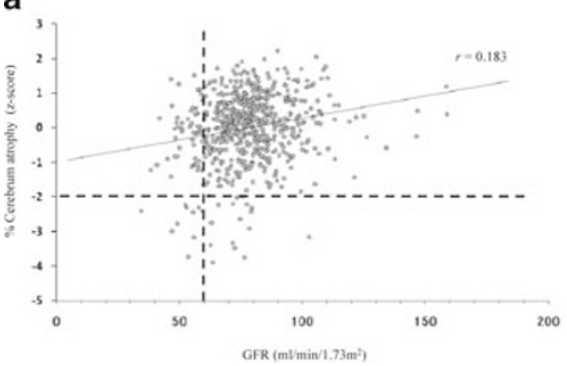

b

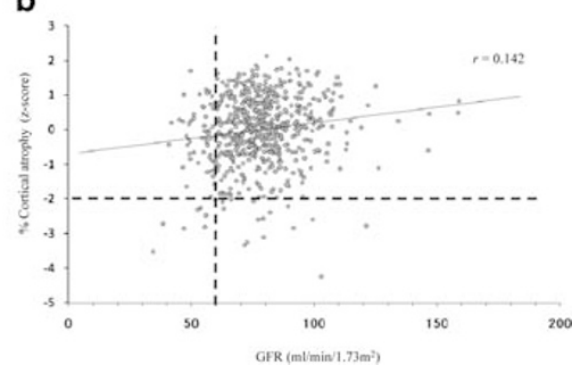

Figure 2 Correlation between GFR and \%Cerebrum atrophy z-score (a), as well as \%Cortical atrophy (b). Linear regression was performed with Spearman's rank correlation, and the regression line is shown. Coefficient of association $=0.183, P<0.001$ (a); $0.142, P<0.001$ (b). A horizontal dotted line suggests a $z$-score of -2.0 . A vertical dotted line suggests a GFR of $60 \mathrm{ml} \mathrm{min}^{-1}$ per $1.73 \mathrm{~m}^{2}$.

Table 3 Logistic regression analysis of factors relevant to periventricular or cortical atrophy

\begin{tabular}{|c|c|c|c|c|c|c|c|c|}
\hline \multirow[b]{3}{*}{ Variables } & \multicolumn{4}{|c|}{ Periventricular atrophy } & \multicolumn{4}{|c|}{ Cortical atrophy } \\
\hline & \multicolumn{2}{|l|}{ Model 1} & \multicolumn{2}{|l|}{ Model 2} & \multicolumn{2}{|l|}{ Model 3} & \multicolumn{2}{|l|}{ Model 4} \\
\hline & OR $(95 \% \mathrm{Cl})$ & $\mathrm{P}$-value & OR $(95 \% \mathrm{Cl})$ & P-value & OR $(95 \% \mathrm{Cl})$ & $\mathrm{P}$-value & OR $(95 \% \mathrm{Cl})$ & $\mathrm{P}$-value \\
\hline GFR (per $10 \mathrm{ml} \mathrm{min}^{-1}$ per $1.73 \mathrm{~m}^{2}$ ) & $0.81(0.55-1.19)$ & 0.282 & $0.81(0.55-1.20)$ & 0.297 & $0.91(0.66-1.26)$ & 0.573 & $0.91(0.66-1.26)$ & 0.578 \\
\hline GFR $<60 \mathrm{ml} \mathrm{min}^{-1}$ per $1.73 \mathrm{~m}^{2}$ & $1.66(0.49-5.63)$ & 0.419 & $1.62(0.47-5.56)$ & 0.445 & $3.23(1.15-9.11)$ & 0.026 & $3.22(1.14-9.11)$ & 0.028 \\
\hline
\end{tabular}

Analyses were adjusted by age, sex, hypertension, WMH and presence of lacunae in Models 1 and 3, and additionally adjusted by the MMSE score in Models 2 and 4 .

function variable was significantly associated with cerebral atrophy in each model (Table 2). Age, male sex and severity of WMH were also significantly associated with cerebral atrophy in each logistic regression analysis. The association between the degree of cerebral atrophy ( $z$-score) and the GFR value is shown in Figure 2a.

For the sub-analysis, logistic regression analysis was performed to examine the association between kidney function variables and periventricular atrophy, as well as cortical atrophy (Table 3). Primary logistic regression analysis was adjusted for age, sex, hypertension, WMH and lacunae. For the final logistic regression analysis, the MMSE score was added to the variables. As a result, GFR $<60 \mathrm{ml} \mathrm{min}^{-1}$ per $1.73 \mathrm{~m}^{2}$ was significantly associated with cortical atrophy in each analysis (Table 3: models 3 and 4). The association between the degree of cortical atrophy ( $z$-score) and the GFR value is shown in Figure 2b.

\section{DISCUSSION}

This is the first study to demonstrate the relationship between decreased GFR and age-specific, generalized cerebral atrophy in adults without neurological disorders. All subjects enrolled in this study were independent in daily life, had no history of neurological disorders and were demonstrated to have normal neurological examinations. The data show that both continuous GFR decrease and GFR $<60 \mathrm{ml} \mathrm{min}^{-1}$ per $1.73 \mathrm{~m}^{2}$ were significantly and independently associated with cerebral atrophy. The effect of GFR on cerebral atrophy appears to be independent of coexisting traditional risk factors for cerebrovascular disease.

A recent population-based cohort study found that decreased GFR had significant associations with decreased deep white matter volume, but not with decreased whole brain volume. ${ }^{12}$ It seems that the inconsistent result for the relationship between brain atrophy and 
GFR is partially due to the difference in the study population and the method of atrophy measurement. However, the major cause of difference may be the classification of atrophy, which was divided into quartiles of brain volume in the previous study, but into two groups using a cutoff point at -2 s.d.s of the mean \%Cerebrum atrophy in this study. Thus, decreased GFR might correlate with marked cerebral atrophy that exceeds a certain threshold.

Although the mechanisms underlying the pathological association between kidney dysfunction and marked cerebral atrophy remain unclear, several hypotheses might explain such an association. First, the similarity of the vascular bed function of the kidney and brain should be considered. The vascular beds of both organs have very low resistance and are passively perfused at high flow throughout systole and diastole. ${ }^{19}$ Such common function might be related to the finding that there is an association between degeneration of both organs, such as CKD or SVD. ${ }^{12}$ Second, endothelial dysfunction might be an influential cofactor for damage of both organs. When the endothelium is damaged, a complex inflammatory and genomic response initiates a positive feedback cycle of injury, immunological induction and amplification. ${ }^{20}$ Such a condition could reduce endothelial nitric oxide synthase activity, which regulates the microcirculation and blood-brain barrier, ${ }^{21}$ and it might contribute to the progression of CKD, as well as SVD. The renin-angiotensin-aldosterone system, which affects blood pressure regulation, vasoconstriction, thrombosis and vessel wall damage, also should be considered as one of the cofactors for degenerative changes in both CKD and SVD. A consensus has emerged that treatment with renin-angiotensin-aldosterone system blockers, such as angiotensin-converting enzyme inhibitors or angiotensin receptor blockers, has a specific renoprotective effect, but the direct efficacy of such regimens on SVD progression has not yet been proven. ${ }^{22,23}$

According to previous reports that demonstrated the association between kidney dysfunction and SVD, ${ }^{8-13}$ it can be also considered that the deterioration of kidney function takes part in cerebral atrophy through the SVD progress. As SVD mainly affects deep perforating arterioles, it was expected that decreased GFR might relate more closely to periventricular atrophy than cortical atrophy. However, in our sub-analysis, a substantial degree of GFR decrease $\left(<60 \mathrm{ml} \mathrm{min}^{-1}\right.$ per $1.73 \mathrm{~m}^{2}$ ) had a significant relevance to cortical atrophy but not to periventricular atrophy. Thus, the influence of kidney dysfunction on cerebral atrophy, in particular cortical atrophy, seems to be caused not only by SVD but also by other pathogenetic mechanisms that were not examined in this study, such as genetic factors and neurotoxic effects caused by elevated homocysteine levels. ${ }^{24,25}$

The present results, which demonstrated that marked cerebral atrophy was strongly associated with aging, male sex and $\mathrm{WMH}$, are consistent with those of previous studies. ${ }^{3,26-28}$ Several populationbased studies have examined the relationship between cerebral atrophy and cognitive decline. ${ }^{29-31}$ However, our logistic regression analysis showed no significant correlation between MMSE score and cerebral atrophy. Such inconsistency in the results may be caused by the relatively younger population (mean age, 56.4 years) in this study. In fact, a previous Japanese population-based study in which most subjects were $>70$ years old demonstrated the effect of cerebral atrophy on cognitive impairment using the same imaging methodology. ${ }^{17}$

This study had several limitations. First, there might have been selection bias. As the present subjects were Japanese adults who sought health screening tests of the brain at their own expense, a possible selection bias may have existed toward individuals who were relatively affluent or had a high degree of concern for their own health. Such bias might have been affected by differences in educational background and socioeconomic status, which are considered risk factors for cardiovascular disease. ${ }^{32}$ The fact that nearly a quarter of all of the individuals who were considered potential study subjects ( $n=199 / 809 ; 24.6 \%)$ were excluded from the analysis could also be a selection bias. On univariate analysis comparison of the included ( $n=610)$ and excluded $(n=199)$ groups (the number of excluded subjects in each evaluation is different; see Supplementary Information), the excluded group seemed to include younger males with a lower prevalence of family history of stroke and shorter duration of education. These differences could be a selection bias. However, there were no differences in the main variables of this study, such as kidney function and MRI findings, between the included and excluded groups. Second, this study was based on a cross-sectional design, which limits the interpretation of our results with respect to cause and effect. Third, to evaluate kidney function, estimated GFR using serum creatinine-based formulas with a single blood sample was used, but the urinary albumin concentration was not used. Although this is common practice in epidemiological studies, it is recommended that, to diagnose CKD, GFR be estimated using multiple serum samples and the diagnosis be confirmed with continuous urinary albumin measurements. Thus, one should be cautious when classifying subjects with $\mathrm{GFR}<60 \mathrm{ml} \mathrm{min}^{-1}$ per $1.73 \mathrm{~m}^{2}$ as having CKD in this study. Fourth, information about the kinds of drugs that were used at baseline, as well as duration of medication, could not be obtained. Considering our result, as well as cohort studies that enrolled neurologically healthy subjects that revealed no significant correlation between hypertension and cerebral atrophy, ${ }^{26,28}$ the effect of hypertension on cerebral atrophy appears to be an interaction with age. ${ }^{1}$ In contrast, interestingly, a previous study that enrolled dialysisdependent patients with kidney disease demonstrated that severity and duration of hypertension could be correlated with cerebral atrophy in middle-aged patients. ${ }^{33}$ Thus, there might be some impact of hypertension (not only presence but also severity or duration) on cerebral atrophy among subjects with kidney dysfunction. Not only antihypertensive drugs (especially renin-angiotensin-aldosterone system blockers) but also antihyperlipidemic drugs (especially statins) might have a preventive effect against $\mathrm{CKD},{ }^{34}$ neuropathological degeneration and cognitive decline. ${ }^{35-37}$ Thus, lack of information about such medications may have been responsible for the result that there was no significant association between cerebral atrophy and hypertension or hyperlipidemia. Finally, as our study sample size was relatively small, categorical variables, such as age (per decade), sex, severity of WMH and subjects with GFR $<60 \mathrm{ml} \mathrm{min}^{-1}$ per $1.73 \mathrm{~m}^{2}$, appeared to have a high odds ratio (approximately two- to fivefold), as well as wide $95 \%$ confidence interval ranges, for predicting cerebral atrophy. Thus, caution should be exercised when interpreting these values, which might be exaggerated.

In conclusion, this cross-sectional study offers the first evidence that decreased GFR, particularly $<60 \mathrm{ml} \mathrm{min}^{-1}$ per $1.73 \mathrm{~m}^{2}$, is significantly associated with a substantial degree of cerebral atrophy, indicating that treatment of CKD might control age-related degenerative processes of the brain. The present results imply that a trial to prevent GFR decline using such drugs might slow cerebral atrophy. Further investigations of this interesting association, which suggests the possibility of prevention, are needed.

\section{CONFLICT OF INTEREST}

The authors declare no conflict of interest.

\section{ACKNOWLEDGEMENTS}

This study was supported in part by a Grant-in-Aid for University Reform from the Ministry of Education, Culture, Sports, Science and Technology of Japan. 
We thank Ms Mitsuko Uematsu, Mr Koji Miyazaki, Ms Mai Miyamoto and the medical staff of Yuai-Kai Oda Hospital for their help in conducting medical interviews, acquiring imaging data and inputting data.

Author contributions: $\mathrm{YY}, \mathrm{YN}, \mathrm{TH}, \mathrm{MN}, \mathrm{MH}, \mathrm{JN}$ and $\mathrm{ME}$ analyzed and interpreted the data ( $\mathrm{YY}$ and $\mathrm{MH}$ completed the statistical analysis). TH and MN performed general and neurological examinations. YY, $\mathrm{HH}$ and $\mathrm{KN}$ drafted the manuscript. All authors have seen and approved the final version of the paper

1 Strassburger TL, Lee HC, Daly EM, Szczepanik J, Krasuski JS, Mentis MJ, Salerno JA DeCarli C, Schapiro MB, Alexander GE. Interactive effects of age and hypertension on volumes of brain structures. Stroke 1997; 28: 1410-1417.

2 Schmidt R, Launer LJ, Nilsson LG, Pajak A, Sans S, Berger K, Breteler MM, de Ridde M, Dufouil C, Fuhrer R, Giampaoli S, Hofman A. Magnetic resonance imaging of the brain in diabetes: the Cardiovascular Determinants of Dementia (CASCADE) study. Diabetes 2004; 53: 687-692.

3 Meyer JS, Rauch GM, Crawford K, Rauch RA, Konno S, Akiyama H, Terayama Y, Haque A. Risk factors accelerating cerebral degenerative changes, cognitive decline and dementia. Int J Geriatr Psychiatry 1999; 14: 1050-1061.

4 Mukamal KJ, Longstreth Jr WT, Mittleman MA, Crum RM, Siscovick DS. Alcohol consumption and subclinical findings on magnetic resonance imaging of the brain in older adults: the cardiovascular health study. Stroke 2001; 32: 1939-1946.

5 Go AS, Chertow GM, Fan D, McCulloch CE, Hsu CY. Chronic kidney disease and the risks of death, cardiovascular events, and hospitalization. N Engl J Med 2004; 351: 1296-1305

6 Manjunath G, Tighiouart H, Ibrahim H, MacLeod B, Salem DN, Griffith JL, Coresh J, Levey AS, Sarnak MJ. Level of kidney function as a risk factor for atherosclerotic cardiovascular outcomes in the community. J Am Coll Cardiol 2003; 41: 47-55.

7 Muntner P, He J, Hamm L, Loria C, Whelton PK. Renal insufficiency and subsequent death resulting from cardiovascular disease in the United States. J Am Soc Nephrol 2002; 13: 745-753.

8 Kobayashi S, Ikeda T, Moriya H, Ohtake T, Kumagai H. Asymptomatic cerebral lacunae in patients with chronic kidney disease. Am J Kidney Dis 2004; 44: 35-41.

9 Seliger SL, Longstreth Jr WT, Katz R, Manolio T, Fried LF, Shlipak M, Stehman-Breen CO, Newman A, Sarnak M, Gillen DL, Bleyer A, Siscovick DS. Cystatin c and subclinical brain infarction. J Am Soc Nephrol 2005; 16: 3721-3727.

10 Wada M, Nagasawa H, Kurita K, Koyama S, Arawaka S, Kawanami T, Tajima K, Daimon $M$, Kato T. Microalbuminuria is a risk factor for cerebral small vessel disease in community-based elderly subjects. J Neurol Sci 2007; 255: 27-34.

11 Knopman DS, Mosley Jr TH, Bailey KR, Jack CR, Schwartz GL, Turner ST. Associations of microalbuminuria with brain atrophy and white matter hyperintensities in hypertensive sibships. J Neurol Sci 2008; 271: 53-60.

12 Ikram MA, Vernooij MW, Hofman A, Niessen WJ, van der Lugt A, Breteler MM. Kidney function is related to cerebral small vessel disease. Stroke 2008; 39: 55-61.

13 Khatri M, Wright CB, Nickolas TL, Yoshita M, Paik MC, Kranwinkel G, Sacco RL, DeCarli C. Chronic kidney disease is associated with white matter hyperintensity volume: the Northern Manhattan Study (NOMAS). Stroke 2007; 38: 3121-3126.

14 Kobayashi S, Okada K, Koide H, Bokura H, Yamaguchi S. Subcortical silent brain infarction as a risk factor for clinical stroke. Stroke 1997; 28: 1932-1939.

15 Yakushiji Y, Nishiyama M, Yakushiji S, Hirotsu T, Uchino A, Nakajima J, Eriguchi M, Nanri Y, Hara M, Horikawa E, Kuroda Y. Brain microbleeds and global cognitive function in adults without neurological disorder. Stroke 2008; 39: 3323-3328.

16 Matsuo S, Imai E, Horio M, Yasuda Y, Tomita K, Nitta K, Yamagata K, Tomino Y, Yokoyama $\mathrm{H}$, Hishida A. Revised equations for estimated GFR from serum creatinine in Japan. Am J Kidney Dis 2009; 53: 982-992.

17 Koga H, Yuzuriha T, Yao H, Endo K, Hiejima S, Takashima Y, Sadanaga F, Matsumoto T, Uchino A, Ogomori K, Ichimiya A, Uchimura H, Tashiro N. Quantitative MRI findings and cognitive impairment among community dwelling elderly subjects. J Neurol Neurosurg Psychiatry 2002; 72: 737-741.
18 Fazekas F, Chawluk JB, Alavi A, Hurtig HI, Zimmerman RA. MR signal abnormalities at $1.5 \mathrm{~T}$ in Alzheimer's dementia and normal aging. AJR Am J Roentgenol 1987; 149: $351-356$.

19 O'Rourke MF, Safar ME. Relationship between aortic stiffening and microvascular disease in brain and kidney: cause and logic of therapy. Hypertension 2005; 46: 200-204.

20 Thompson CS, Hakim AM. Living beyond our physiological means: small vessel disease of the brain is an expression of a systemic failure in arteriolar function: a unifying hypothesis. Stroke 2009; 40: e322-e330.

21 Wardlaw JM, Sandercock PA, Dennis MS, Starr J. Is breakdown of the blood-brain barrier responsible for lacunar stroke, leukoaraiosis, and dementia? Stroke 2003; 34: 806-812.

22 Dufouil C, Chalmers J, Coskun O, Besançon V, Bousser MG, Guillon P, MacMahon S, Mazoyer B, Neal B, Woodward M, Tzourio-Mazoyer N, Tzourio C, PROGRESS MRI Substudy Investigators. Effects of blood pressure lowering on cerebral white matter hyperintensities in patients with stroke: the PROGRESS (Perindopril Protection Against Recurrent Stroke Study) Magnetic Resonance Imaging Substudy. Circulation 2005; 112: $1644-1650$

23 Firbank MJ, Wiseman RM, Burton EJ, Saxby BK, O'Brien JT, Ford GA. Brain atrophy and white matter hyperintensity change in older adults and relationship to blood pressure. Brain atrophy, WMH change and blood pressure. J Neurol 2007; 254: 713-721.

24 Suliman ME, Lindholm B, Barany P, Qureshi AR, Stenvinkel P. Homocysteine-lowering is not a primary target for cardiovascular disease prevention in chronic kidney disease patients. Semin Dial 2007; 20: 523-529.

25 den Heijer T, Vermeer SE, Clarke R, Oudkerk M, Koudstaal PJ, Hofman A, Breteler MM. Homocysteine and brain atrophy on MRI of non-demented elderly. Brain 2003; 126: 170-175.

26 Enzinger C, Fazekas F, Matthews PM, Ropele S, Schmidt H, Smith S, Schmidt R. Risk factors for progression of brain atrophy in aging: Six-year follow-up of normal subjects. Neurology 2005; 64: 1704-1711.

27 Coffey CE, Lucke JF, Saxton JA, Ratcliff G, Unitas LJ, Billig B, Bryan RN. Sex differences in brain aging: a quantitative magnetic resonance imaging study. Arch Neurol 1998; 55: 169-179.

28 Longstreth Jr WT, Arnold AM, Manolio TA, Burke GL, Bryan N, Jungreis CA, O'Leary D, Enright PL, Fried L. Clinical correlates of ventricular and sulcal size on cranial magnetic resonance imaging of 3,301 elderly people. The Cardiovascular Health Study. Collaborative Research Group. Neuroepidemiology 2000; 19: 30-42.

29 Breteler MM, van Amerongen NM, van Swieten JC, Claus JJ, Grobbee DE, van Gijn J, Hofman A, van Harskamp F. Cognitive correlates of ventricular enlargement and cerebral white matter lesions on magnetic resonance imaging. The Rotterdam study. Stroke 1994; 25: 1109-1115.

30 Kuller LH, Shemanski L, Manolio T, Haan M, Fried L, Bryan N, Burke GL, Tracy R, Bhadelia R. Relationship between ApoE, MRI findings, and cognitive function in the Cardiovascular Health Study. Stroke 1998; 29: 388-398.

31 Seshadri S, Wolf PA, Beiser A, Elias MF, Au R, Kase CS, D'Agostino RB, DeCarli C. Stroke risk profile, brain volume, and cognitive function: the Framingham Offspring study. Neurology 2004; 63: 1591-1599.

32 Winkleby MA, Kraemer HC, Ahn DK, Varady AN. Ethnic and socioeconomic differences in cardiovascular disease risk factors: findings for women from the Third National Health and Nutrition Examination Survey, 1988-1994. JAMA 1998; 280: 356-362.

33 Savazzi GM, Cusmano F, Bergamaschi E, Vinci S, Allegri L, Garini G. Hypertension as an etiopathological factor in the development of cerebral atrophy in hemodialyzed patients. Nephron 1999; 81: 17-24.

34 Nguyen T, Toto RD. Slowing chronic kidney disease progression: results of prospective clinical trials in adults. Pediatr Nephrol 2008; 23: 1409-1422.

35 Spence JD. Preventing dementia by treating hypertension and preventing stroke. Hypertension 2004; 44: 20-21.

36 Bernick C, Katz R, Smith NL, Rapp S, Bhadelia R, Carlson M, Kuller L. Statins and cognitive function in the elderly: the Cardiovascular Health Study. Neurology 2005; 65 : 1388-1394.

37 Li G, Larson EB, Sonnen JA, Shofer JB, Petrie EC, Schantz A, Peskind ER, Raskind MA Breitner JC, Montine TJ. Statin therapy is associated with reduced neuropathologic changes of Alzheimer disease. Neurology 2007; 69: 878-885.

Supplementary Information accompanies the paper on Hypertension Research website (http://www.nature.com/hr) 